\title{
A key to the Afrotropical genera of Muscidae (Diptera)
}

\section{Márcia S. Couri}

M useu Nacional, Universidade Federal do Rio de Janeiro. Quinta da Boa Vista, 20940-040 Rio de Janeiro, Rio de Janeiro, Brasil. Fellow of CNPq. E-mail:mcouri@attglobal.net

\begin{abstract}
A key to 57 of the 58 Afrotropical Muscidae (Diptera) genera is given. The previous Catalogue of Afrotropical Diptera published about 25 years ago by Adrian C. Pont was used as a taxonomic guide, to which the more recently synonyms and taxonomic changes were updated. For each genus, geographical distribution and number of valid species in this region are also included. Some morphological diagnostic characters are illustrated in order to help the use of the key.

KEY WORDS. Afrotropical Region, Identification, taxonomy.

RESUMO. Chave para os gêneros afrotropicais de Muscidae (Diptera). Uma chave para 57 dos 58 gêneros Afrotropicais de Muscidae (Diptera) é apresentada. O catálogo afrotropical de Diptera publicado a cerca de 25 anos atrás por Adrian C. Pont foi utilizado como guia taxonômico, ao qual foram acrescentados sinônimos e mudanças taxonômicas recentes. Para cada gênero são incluídos o número de espécies válidas e a distribuição geográfica nesta região. Alguns caracteres morfológicos diagnósticos são ilustrados para facilitar a utilização da chave. PALAVRAS-CHAVE. Identificação, Região Afrotropical, taxonomia.
\end{abstract}

Thetaxonomic knowledge of the Afrotropical muscids can befound in EMden (1939, 1940, 1941, 1942a,b, 1943, 1951) and, more recently, in ZieLKe (1971) for the Muscini, DeEming (1971) for the "Atherigonini" and Zumpt (1973) for the "Stomoxyinae". Species have been described by Crosskey; Deeming; Emden, Paterson, Peris, Pont, Snyder, Zielke and Zumpt and keys have been presented by Zum PT (1969) for Aethiopomyia Malloch, 1921; PATERSON (1960) for Allaudinella Giglio-Tos, 11895, SNYDER (1953) for Mydaea Robineau-Desvoidy, 1830 (in part); Pont \& DeAr (1976) for Ochromusca Malloch, 1927; Pont (1974) for Passeromyia Rodhain \& Villeneuve, 1915; CROSSKEY (1962) for Pygophora Schiner, 1868, among others (PONT 1980).

The latest consolidated information on the Afrotropical muscid fauna is found in PONT (1980), where about 870 valid species (herein atualized to 925) are recorded to the Region, occuring in all available habitats, except for the most arids. The muscids represent some of the most abundant and widespread flies in Africa (Pont 1980).

The information on the madagascan muscid fauna were updated by Courı et al. (2006), where 23 new species were de scribed, seven species and three genera were newly recorded from Madagascar (Azelia Robineau-Desvoidy, Phaonia RobineauDesvoidy and Spilogona Schnabl); two replacement names were given to two homonimies and one new synonym was stablished. The paper also presented a key for all included genera and species. Most of the material studied was collected by the "Madagascar Arthropod Biodiversity Project" developed by the California Academy of Sciences (San Francisco, California) from the beginnig of 2001 until early 2005.

Certainly the Afrotropical muscid fauna is much richer than these numbers. Among the madagascan material there are still taxa to be described, including some Atherigona species, a genus well represented in the Region. More collections in the whole Region will certainly make other new taxa known.

Presently, about $75 \%$ of the recorded afrotropical muscid genera are represented for less than 10 species, while genera as Atherigona Rondani, 1856, Coenosia Meigen, 1826 and Helina Robineau-Desvoidy, 1830 are represented, respectively, by 126, 111 and 99 species.

For the present key, the Catal ogue of Afrotropical Diptera (Pont 1980) was used as a taxonomic guide, to which, the more recently synonyms and taxonomic changes were updated (see Couri et al. 2006). The terminology follows McAlpine et al. (1981).

Table I summarizes the valid muscid genera and subgenera of the Afrotropical Region by subfamily and the number of species based on PONT (1980) for the whole Region and Courl et al. (2007) for Madagascar and other synonymies (including Ophyra Robineau-Desvoidy as a junior synonym of Hydrotaea Robineau-Desvoidy); Courı \& Pont $(1999,2000)$ for Coenosiinae and Carvalho et al. (2005) for general classification.

As a result, 57 of the 58 recorded genera are keyed. Data on geographical records and number of valid species in the Afrotropical Region were included in the key. Some morphological diagnostic characteres were illustrated in order to help the use of the key.

Revista Brasileira de Zoologia 24 (1): 175-184, março 2007 
Table I. Valid Muscidae genera and subgenera of the Afrotropical Region and number of species (classification as in PoNT 1980, Courv et al. 2006, Couri \& Pont 2000 and CarvalHo et al. 2005).

\begin{tabular}{|c|c|c|c|}
\hline Subfamily, genera and subgenera & Number of species & Subfamily, genera and subgenera & Number of species \\
\hline Atherigoninae & & Synthesiomyia Brauer \& Bergenstamm & 1 \\
\hline Atherigona Rondani & & Phaoninae & \\
\hline Acritochaeta Grimshaw & 14 & Aethiopomyia Malloch & 5 \\
\hline Atherigona Rondani & 112 & Allaudinella Giglio-Tos & 6 \\
\hline Muscinae & & Dichaetomyia Malloch & \\
\hline Muscini & & Dichaetomyia Malloch & 37 \\
\hline Curranosia Paterson & 7 & Panaga Curran & 30 \\
\hline Dasyphora Robineau-Desvoidy & 1 & Helina Robineau-Desvoidy & 99 \\
\hline Deltotus S,guy & 3 & Ochromusca Malloch & 2 \\
\hline Hennigmyia Peris & 3 & Phaonia Robineau-Desvoidy & 26 \\
\hline Mitroplatia Enderlein & 9 & Mydaeinae & \\
\hline Morellia Robineau-Desvoidy & 15 & Afromydaea Malloch & 2 \\
\hline Musca Linnaeus & & Brontaea Kowarz & 23 \\
\hline Byomya Robineau-Desvoidy & 21 & Dimorphia Malloch & 5 \\
\hline Eumusca Townsend & 10 & Graphomya Robineau-Desvoidy & 13 \\
\hline Lissosterna Bezzi & 1 & Hebecnema Schnabl & 7 \\
\hline Musca Linnaeus & 1 & Myospila Rondani & 18 \\
\hline Philaematomyia Austen & 1 & Pseudohelina Vockeroth & 9 \\
\hline Viviparomusca Townsend & 5 & Coenosiinae & \\
\hline Neomyia Walker & 43 & Limnophorini & \\
\hline Polietes Rondani & 1 & Andersonosia Emden & 2 \\
\hline Pyrellia Robineau-Desvoidy & 12 & Camptotarsopoda Strand & 5 \\
\hline Pyrellina Malloch & 12 & Limnophora Robineau-Desvoidy & 76 \\
\hline Unplaced Muscini & 1 & Lispacoenosia Snyder & 4 \\
\hline Stomoxyini & & Lispe Latreille & 50 \\
\hline Bruceomyia Malloch & 1 & Spilogona Schnabl & 18 \\
\hline Haematobia Le Peletier $\&$ Serville & 6 & Xenomyia Malloch & 15 \\
\hline Haematobosca Bezzi & 9 & Coenosiini & \\
\hline Parastomoxys Zumpt & 1 & Amicitia Emden & 4 \\
\hline Prostomoxys Zumpt & 1 & Anaphalanthus Loew & 1 \\
\hline Rhinomusca Malloch & 2 & Brevicosta Malloch & 1 \\
\hline Stomoxys Geoffroy & 14 & Cephalispa Malloch & $3 *$ \\
\hline Stygeromyia Austen & 2 & Coenosia Meigen & 111 \\
\hline Azeliinae & & Lispocephala Pokorny & 3 \\
\hline Azeliini & & Microcalyptra Stein & 3 \\
\hline Azelia Robineau-Desvoidy & 2* & Orchisia Rondani & 1 \\
\hline Fraserella Steyskal & $1^{*}$ & Pygophora Schiner & 6 \\
\hline Hydrotaea Robineau-Desvoidy & 22 & Schoenomyza Haliday & 1 \\
\hline Reinwardtiini & & Spanochaeta Stein & 1 \\
\hline Muscina Robineau-Desvoidy & 2 & New genus & 1 \\
\hline Passeromyia Rodhain \& Villeneuve & 1 & Total & 925 \\
\hline
\end{tabular}

* One not identified.

Revista Brasileira de Zoologia 24 (1): 175-184, março 2007 
Polietes Rondani, 1866 was not included in the key, as no material was examined and the available data in literature was not sufficient. It is represented in the Afrotropical Region by only one species - P. Iardaria (Fabricius, 1781). The genus has the prosternum haired on sides, fine hairs on the upper anterior angle of meron; female has cruciate interfrontal setae and two or more proclinate outer setae on each orbit.

The key is mainly based on Courı et al. (2006), where the other Afrotropical Muscidae not recorded to Madagascar were included, and has also parts modified from EMDEN (1939, 1940, 1951), ZuMPt (1973) (Stomoxyiinae), CourI \& PONT (1999), Carvalho \& Couri (2002) and Couri \& Carvalho (2002).

\section{Key to the Afrotropical genera of Muscidae}

1. Proboscis usually el ongated, strong sclerotized; label a reduced; mouth parts modified into a piercing organ; prosternum and anepimeron setulose; arista with long hairs on the dorsal surface and bare on ventral or, at most with 3-4 ventral cilia (except in Rhinomusca and Haematobosca) 2

1 '. Proboscis retractile, not modified into a piercing organ, faintly or moderately sclerotized; prosternum and anepimeron setulose or bare; arista bare, with short hairs or plumose

2. Palpus about as long as proboscis (Fig. 1) 3

2 '. Palpus shorter than half of the proboscis length; 14 species (widespread in Afrotropical Region, including Cape Verde Is., Madagascar, Mauritius, Réunion, Seychelles, St. Helena, South Yemen) Stomoxys Geoffroy

3. Palpi strap-like, not grooved internally..... 4

3'. Palpi grooved internally, strap-like or more or less dilated terminally .. 7

4. Postalar wall with a tuft of black hairs; arista with long dorsal and ventral hairs; propleuron setulose; katepisternal anterior seta absent; 2 species (associated with rhinocerous in east and southern Africa) (Kenya, South Africa) ............

Rhinomusca Malloch

4'. Postalar wall bare; arista with dorsal and ventral hairs or only dorsal hairs; propleuron bare or setulose; katepisternal anterior seta present or absent

5

5. Propleuron bare; katepisternal anterior seta present; 1 species (Uganda, Sudan, Zaire) Bruceomyia Malloch

5'. Propleuron setulose; katepisternal anterior seta present or absent

6

6. Katepisternal anterior seta present; arista with dorsal hairs only; general body color black and orange; body length 6 mm; 1 species (M ozambique) ............ Parastomoxys Zumpt

6. Katepisternal anterior seta absent; arista with dorsal hairs only, or with few short ones ventrally; general body color dark; body length 3.5-4.5 mm; 1 species (Zaire) Prostomoxys Zumpt

7. Katepisternal anterior seta absent; arista with dorsal hairs only; propleuron and notopleuron setulose; 2 species
(Kenya, South Africa, South Yemen, Rhodesia, Somalia, Sudan, Zaire, widespread east to southern Afrotropical Region) . Stygeromyia Austen

7'. Katepisternal anterior seta present; arista with dorsal and ventral cilia, or only dorsal; propleuron and notopleuron setulose or bare

8. Arista with dorsal and ventral hairs, notopleuron with covering setulae; propleuron setulose or bare; general body color from yellow to black; body length between 3.5-9.0 mm, 9 species (Cameroun, Kenya, Malawi, Rhodesia, South Africa, Tanzania, Uganda, Zaire, widespread east to southen Afrotropical Region) .......................... Haematobosca Bezzi

8'. Arista with dorsal hairs only, notopleuron without covering setulae (but setae present); propleuron bare; general body color with dense grey and oliver pollinosity; body length between 2.0-5.0 mm, 6 species (widespread Afrotropical Region, including Socotra, South Yemen)

Haematobia Le Peletier and Serville

9. Head angular in profile; antenna long; antennal insertion above mid-level of eye (Fig. 2); dorsocentral presutural setae very short and fine, almost indistinct from the covering setulae, 126 species (widespread in Afrotropical Region, including Cape Verde Is., Comoro Is., Madagascar, Mauritius, Réunion, Seychelles, South Yemen)

Atherigona Rondani

9a. Palpi of male elongated, flattened (Fig. 3); presutural acrostichal setulae often in 4-5 rows; basal lateral setae of scutellum usually almost or quite half as long as subbasal lateral seta; crossvein r-m usually at or beyond middle of cell dm; forefemur often with a shallow dorsal preapical excavation; adult males without a trifoliate process and hypopygial prominence, 14 species ........

Subgenus Acritochaeta Grimshaw

9a'. Palpi of male club-like (Fig. 4), strikingly swollen on apical half; presutural acrostichal setulae al ways in 2-3 rows; basal lateral setae of scutellum at most one third as long as subbasal lateral seta; cross vein r-m always well in basal half of cell dm; forefemur without a dorsal preapical excavation; adult males with a trifoliate process and hypopygial prominence, 112 species ...... Subgenus Atherigona Rondani

9'. Head shape not as above; antennal insertion below midlevel of eye; dorsocentral presutural setae developed or not differentiated from the covering setulae ...................... 10

10. Anepimeron setulose ............................................ 11

10'. Anepimeron bare....................................................... 27

11. Lower calypter of the Musca-type, i.e. the inner margin at first following the margin of the scutellum then diverging suddenly outward into the more or less broadly truncated apical margin (Fig. 5) (relative smaller in Pyrellina, but katepisternals 1:3)

11'. Lower calypter of the Phaonia-type, i.e. the inner margin

Revista Brasileira de Zoologia 24 (1): 175-184, março 2007 
diverging immediately and at right-angles from the suprasquamal ridge, and tongue-like in shape ..................... 22

12. Palpi yellow; tibiae yellow; antennae orange, flagellomere sometimes infuscated towardstip; arista short-plumose, the longest individual hairs equal to width of antennal flagellomere; stem-vein bare; female without proclinate orbital setae; 6 species (widespread Afrotropical Region including Fernando Póo, Madagascar, Mauritius, Réunion, Seychelles) ................................... Alluaudinella Giglio-Tos

12'. Palpi black; legs entirely black; antennae black; the other characters not present in combination ....................... 13

13. Body shining metallic green or blue; mid tibia with a strong ventral seta .. 14

13'. Body black or bluish-black, not metallic shining green or blue; mid tibia without a ventral seta ........................... 19

14. Suprasquamal ridge setulose ..................................... 15

14'. Suprasquamal ridge bare .......................................... 16

15. Infra-alar bulla setulose; 43 species (widespread in Afrotropical Region, including Cape Verde Is., Fernando Póo, Liberia, Madagascar, Mauritius, Réunion, Rodriguez) ....... Neomyia Robineau-Desvoidy

15'. Infra-alar bulla bare; 7 species (Cameroun, Guinea-Bissau, Ivory Coast, Kenya, M ozambique, Rhodesia, Tanzania, Uganda, Zaire, widespread west Afrotropical Region, including Fernando Póo) ..... Curranosia Paterson

16. Katepisternals $1: 3$ .. 17

16'. Katepisternals different from 1:3. .. 18

17. Lower calypter very broad; cercal plate of male without spined ventral process; 12 species (Cameroun, Kenya, Ghana, Madagascar, South Africa, Tanzania, Uganda, widespread east to southern Afrotropical Region) Pyrellia Robineau-Desvoidy

17'. Lower calypter relativelly smaller; cercal plate of male with spined ventral process (Fig. 6); 12 species (widespread Afrotropical Region including Fernando Póo, Principe) ... Pyrellina Seguy

18. .... Prostenum very wide, much wider than high; 9 species (Cameroun, Mozambique, Rhodesia, South Africa, Sudan, Tanzania, Uganda, Zaire, Zambia) ... Mitroplatia Enderlein

18'. Prosternum not widened; 1 species (St. Helena) ................ Dasyphora Robineau-Desvoidy

19. Eyes widely separated in both sexes; general body color brownish to yellow to rufous, the dorsum of the thorax more or less infuscated or with darker stripes; robust flies ...... 20

19'. Male usually holoptic; general body color blackish, very rarely the ground color of the body pale; more delicate flies .. 21

20. Propleuron setulose; vein $M$ slightly curved forward towards $\mathrm{R}_{4+5} ; 5$ species (Angola, Cameroun, Kenya, Malawi, Mozambique, Tanzania, Togo, Zaire, east and widespread maninland Afrotropical Region) Aethiopomyia Malloch
20'. Propleuron bare; vein M strongly curved forward towards $R_{4+5}$, not much wider than length of $r-m$ cross vein; 2 species (widespread Afrotropical Region, including Fernando Póo) Ochromusca Malloch

21. Vein $M$ with an angular forward bend towards vein $R_{4+5}$ (Figs 7 and 8); 39 species)(widespread in Afrotropical Region, including Cape Verde Is., Madagascar, Mauritius, Réunion, Rodriguez, Socrota, South Yemen) ............ Musca Linnaeus

21a. Proepisternum hairy (Fig. 9); suprasquamal ridge bare; front tibia without a submedian posteroventral seta; mid tibia without a submedian anteroventral seta; mesonotum with four black long vittae; 1 species .....

Subgenus Musca Linnaeus

21a'. Proepisternum bare; suprasquamal ridge bare or hairy; front tibia with or without a submedian posteroventral seta; mid tibia with or without a submedian anteroventral seta $21 b$

21b. Suprasquamal ridge entirely bare ....................... 21c

21b'. Suprasquamal ridge with bristly hairs on anterior part or on anterior and posterior parts ....................... $21 \mathrm{e}$

21c. C. Katerpisternal setae absent; 1 species .................... Subgenus Lissosterna Bezzi

$21 c^{\prime}$. Katerpisternal setae present ............................. 21d

21d. Mid tibia without a distinct anteroventral submedian seta; proboscis normal or slender, mentum less than twice as high as flagellum; 21 species

...................... Subgenus Byomya Robineau-Desvoidy

21d'. Mid tibia with a distinct anteroventral submedian seta; proboscisstout, mentum about twiceas high as flagellum; 1 species Subgenus Philaematomyia Austen

21e. Suprasquamal ridge without erect hairs on posterior part; 10 species............. Subgenus Eumusca Twonsend

$21 e^{\prime}$. Suprasquamal ridge with erect bristly black hairs on anterior part and posterior (Fig. 10); 5 species

Subgenus Viviparomusca Townsend

21 '. Vein $M$ with a smoothly rounded forward curve towards vein $\mathrm{R}_{4+5}$ as in Fig. 11; 15 species (widespread in the Afrotropical Region, including Fernando Póo and Madagascar) .. .. Morellia Robineau-Desvoidy

22. Post humeral seta absent; 15 species (Kenya, Uganda, Tanzania, South Africa, Ivory Coast, Nigeria, Ethiopia) [X. pseudolispe Emden, 1951 recorded from Kenya is the only Xenomyia species with anepimeron setulose]

Xenomyia Malloch, p.p.

22 . Post humeral seta present 23

23. Pal pus greatly enlarged in apical part, spoon-like; parafacial with setulae; prosternum bare; 50 species (widespread in the Afrotropical Region including Cape Verde Is, Madagascar, and Mauritius) ................................... Lispe Latreille

23'. Palpus not enlarged, narrow; parafacial bare; prosternum setulose 24 

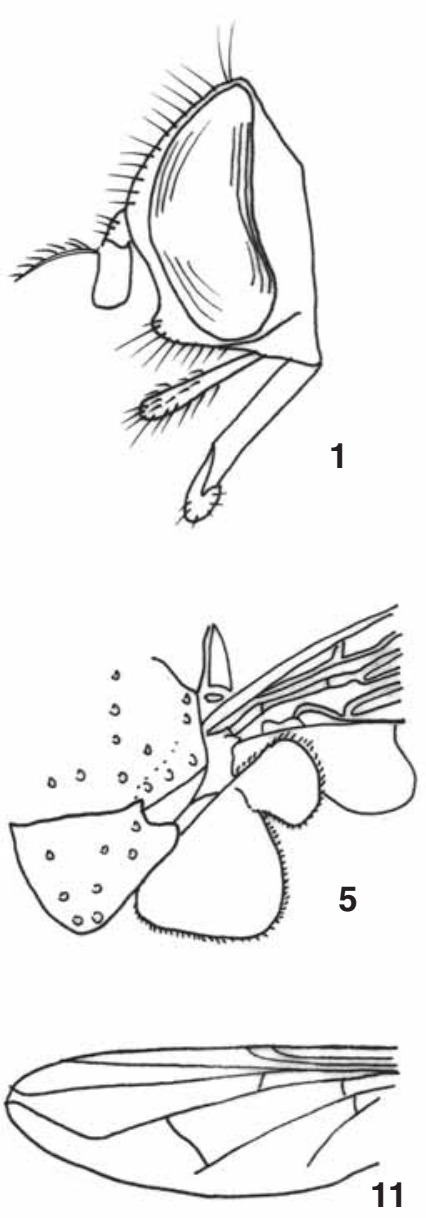

11

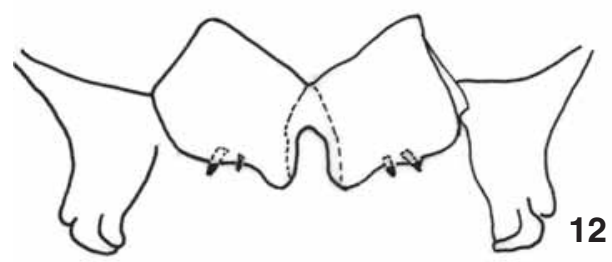

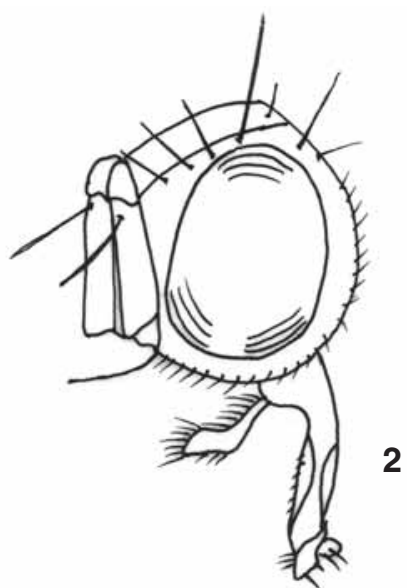
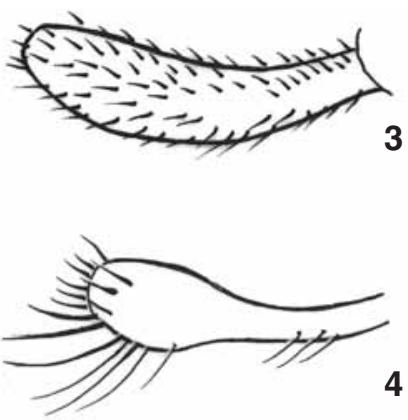

2
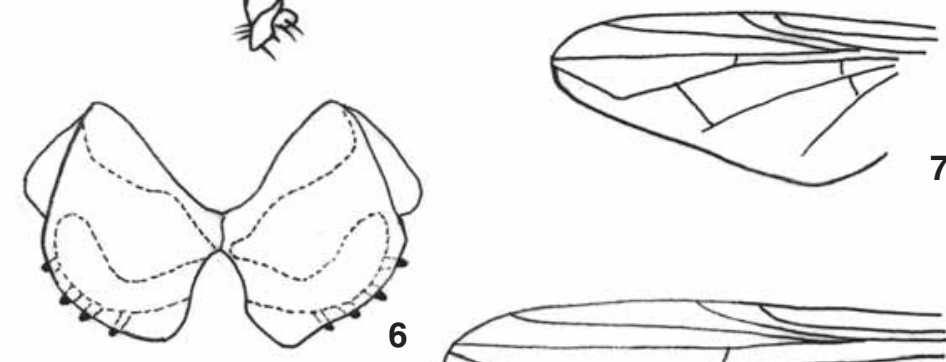

7

6
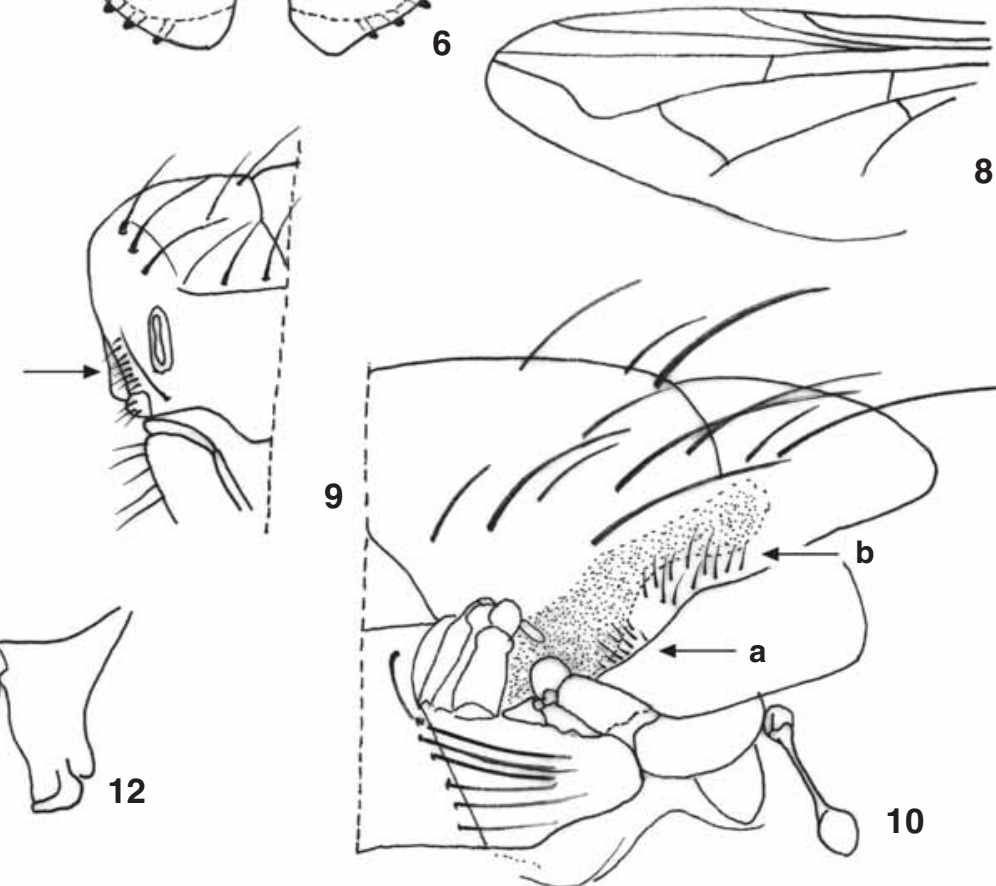

Figures 1-12. (1) Haematobosca, head, lateral view; (2) Atherigona, head, dorsolateral view (modified from PonT \& MAGPAYO 1995); (3) Atherigona (Acritochaeta) orientalis Schiner, 1868, palpus of female (modified from EMDEN 1940); (4) Atherigona (Atherigona) perfida Stein, 1913, palpus of male (modified from Emden 1940); (5) Musca (Musca) domestica Linnaeus, 1758, upper and lower calypters (modified from Mcalpine 1981); (6) Pyrellina garmsi Zielke, 1971, cercal plate of male, frontal view (modified from ZielKE 1971); (7) M usca (Byomyia) afra Paterson, 1956, wing (modified from ZletKe 1971); (8) M usca (Viviparomusca) gabonensis Macquart, 1855. Wing (modified from ZielKe 1971); (9) Musca (Musca) domestica Linnaeus, 1758, anterior part of thorax, lateral view (proepisternal hairs indicated) (modified from Emden 1939); (10) M usca (Viviparomusca) gabonensis Macquart, 1855, hind part of mesonotum: (a) anterior suprasquamal setae, (b) posterior suprasquamal setae (modified from EmDEN 1939); (11) M orellia cerciformis Zielke, 1971, wing (modified from ZielKE 1971); (12) Deltotus stuckenbergi Zielke, 1972, cercal plate and surstili of male, frontal view (modified from ZleKKE 1972). 
24. Vein $\mathrm{R}_{1}$ bare dorsally 25

24 '. Vein $R_{1}$ setulose dorsally .. 26

25 . Wing veins setulose as follows: $R$ with $2-3$ fine setae on lower surface before humeral cross vein; $R_{4+5}$ with 3-5 fine setae below on basal third, the setae beginning at some distance beyond the node of Rs; other veins bare above and below; 3 or 4 pairs of postsutural dorsocentral setae; acrostichals 3:3, strongly developed; 9 species (Burundi, Cameroun, Kenia, Rhodesia, São Tomé, South Africa, Tanzania, Uganda, Zaire, widespread east to southern and mainland in Afrotropical Region) ..... Pseudohelina Vockeroth p.p.

$25^{\prime}$. Wing veis not setulose as above; 2,3 or 4 pairs of postsutural dorsocentral setae; acrostichals not 3:3; 67 species (widespread in the Afrotropical Region including Comoro Is., Madagascar and Seychelles) ............ Dichaetomyia Malloch

25a. Callus prealar setulose or with some stiff hairs; 30 species Subgenus Panaga Curran

25a'. Callus prealar bare; 37 species Subgenus Dichaetomyia Malloch

26. Two pairs of postsutural dorsocentral setae; male cercal plate with 2 marginal spines (Fig. 12) (male of D. facetus unknown); female frons with a pair of proclinate orbital setae; 3 species (Madagascar) Deltotus Seguy

26'. Four pairs of postsutural dorsocentral setae; male cercal plate without spines, with normal setae and setulae; 3 species (Fernando Póo, South Africa, Tanzania, Uganda) .

Hennigmyia Peris

27. Hind coxa with setulae present on posterior apical margin; 2 species 91 not identified) (Uganda, Madagascar) Azelia Robineau-Desvoidy

27'. Hind coxa bare on posterior apical margin .................. 28

28. Wing with the subcosta running in a smooth even curve from humeral cross-vein to costa;; body colour metallic black, blue or green; gena with or without a strong differentiated upcurved seta; female ocellar triangle shining, long or short, almost reaching lunula, and frons with a pair of proclinate orbital setae and inclinate interfrontal setae; 22 species (Cameroun, Ethiopia, Ghana Kenya, Mauritius, Rhodesia, South Africa, Tanzania, Uganda, Zaire, widespread in Afrotropical Region, including Fernando Póo, St. Helena, Socotra, Madagascar, Mauritania, Réunion, Rodriguez, Seychelles) ......................... Hydrotaea Robineau-Desvoidy

28'. Wing with the subcosta with a slightly sinuous course from humeral cross-vein to costa, not smoothly bowed; body colour usually not metallic black, blue or green; gena without a differentiated upcurved seta; female ocellar triangle usually short, and frons without proclinate orbital or inclinate interfrontal setae

29.Wing with at least one setula on ventral surface of Rs node or base of vein $\mathrm{R}_{4+5}$ 30

29'. Wing without setulae on ventral surface of Rs node or base of vein $R_{4+5}$ 40
30.Vein $R_{4+5}$ with several setulae on base, these sometimes absent on upper wing surface; male dichoptic; postalar wall setulose or bare, arista short, long plumose, the dorsal plumes longer and sparse than the ventrals; 1 species (Zambia, widespread mainland neotropical) .. Passeromyia Rodhain and Villeneuve

30'. Vein $\mathrm{R}_{4+5}$ not setulose as described above; male holoptic or dichoptic; post-alar wall not setulose; plumae of arista not as described above. 31

31. Prosternum with lateral setulae; prealar seta absent; 76 species (widespread in the Afrotropical Region, including Canary Is., Cape Verde Is. Madagascar, Mauritius, Réunion, Socotra, South Yemen) ..... Limnophora Robineau-Desvoidy

31'. Prosternum bare or only with 1-2 setulae on either side; prealar seta present or absent. 32

32. Dorsocentrals postsutural usually 4; tibiae often partly creamy-white; male: mid leg modified (Fig. 13), the femora (except in pallipes) between middleand apex with an anterior notch, the proximal edge of which is adorned with some strong setae, the metatarsus curved owing to a broad ventral emargination, the apex somewhat tooth-shaped and with some stiff setulae; halter pale; frons with only one pair of inclinate frontal setae, which are strong; female: frons without cruciate or convergent interfrontal and proclinate orbital setae; 5 species (Burundi, Kenya, Rwanda, South Africa, Tanzania, Uganda, Zaire) ... Camptotarsopoda Strand

32'. Dorsocentrals postsutural 3 or 4; tibiae not partly creamywhite; male mid leg simple; halter pale or black; frons with 1 or 2 pairs of inclinate frontal setae, which are strong; female: frons with or without cruciate or convergent interfrontal and proclinate orbital setae 33

33. Slender Lispoides forms with abnormal characters: either no posthumeral seta present, or a sub-median posterodorsal on hind tibia; or spotted (i.e. not only smoke) wings (Fig. 14); or greatly developed parafrontalia (Fig. 15); which in the male reduce the interfrontalia to a narrow groove and even in the female are much wider in front than in interfrontalia; or with setulose anepimeron (only in X. pseudolispe Emden, see couplet 23); or claws longer than third antennal joint or the peristomal setae small and hair like along part of the mouth margin, usually several of the characters present at thesametime (modified from Emden 1951); 15 species (Kenya, Uganda, Tanzania, South Africa, Ivory Coast, Nigeria, Ethiopia) Xenomyia Malloch p.p.

33'. Other combination of characters 34

34. Anterior katepisternal seta absent; lower calypter broad and truncated, Musca-type (see above, couplet 11a); vein $R_{4+5}$ without dorsal setulae; 13 species (widespread in the Afrotropical Region, including Cape Verde Is., Madagascar, Mauritius) Graphomya Robineau-Desvoidy

34'. Anterior katepisternal seta present; Iower calypter not broad and truncated, tonge-shaped, Phaonia-type (see above,

Revista Brasileira de Zoologia 24 (1): 175-184, março 2007 


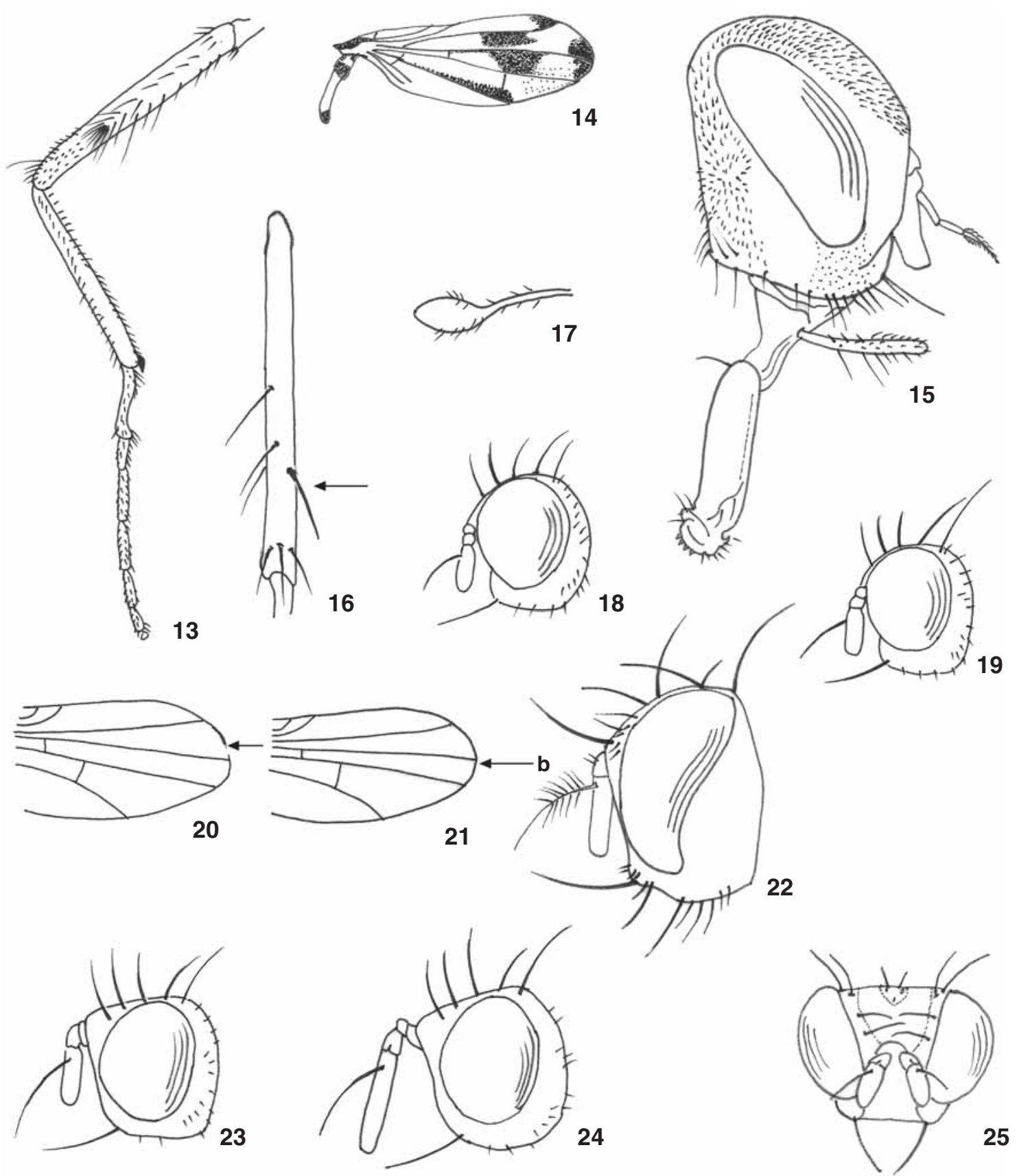

Figures 13-25. (13) Camptotarsopoda annulitarsis (Emden,1951), mid leg of male, anterior view (modified from EMDEN 1951); (14) Xenomyia calyptrata Emden, 1951, wing of male (modified from EmDEN 1951); (15. Xenomyia edwardsi Emden, 1951, head of male, lateral view (modified from Emden 1951); (16) Phaonia, hind leg posterior view (calcar indicated); (17) Lispacoenosia fulvitarsus Snyder, 1949, palpus (modified from SNYDER 1949); (18) Coenosiini, head with two pairs of reclinate orbital seta (modified from CounI \& PonT 1999); (19) Coenosiini, head with one pair of reclinate orbital seta (modified from CouRI \& PONT 1999); (20) Brevicosta, posterior part of the wing; end of Costal vein indicated (modified from CourI \& PONT 1999); (21) Coenosiini, posterior part of the wing; end of Costal vein indicated (modified from CouRI \& PONT 1999); (22) Pygophora pallipalpis (Stein, 1910), head, lateral view (modified from CROSSKEY 1962); (23) Amicitia, head, lateral view (modified from Cour \& PONT 1999); (24) Anaphalanthus, head, lateral view (modified from CouRl \& Pont 1999); (25) Schoenomyza, head, frontal view (modified from Cour \& PONT 1999). 
couplet 11b); $R_{4+5}$ with a few dorsal setulae basally ..... 35

35. Veins Sc, Rs and M setulose, usually as follows: vein $R$ before humeral cross-vein, on both surfaces; on the basal part of $\mathrm{Sc}$, on both surfaces; ventral surface of $\mathrm{R}_{4+5}$ almost to crossvein $\mathrm{r}-\mathrm{m}$; on both surfaces of $M$ to beyond cross-vein $\mathrm{dm}$ $\mathrm{Cu}$; and on ventral surface of $\mathrm{Cu} ; .5$ species (widespread east to southern in the Afrotropical Region, including Mauritius, Madagascar and Congo Basin) ........... Dimorphia Malloch

35'. Wing veins not setulose as described above ................. 36

36. Hind tibia with a strong posterodorsal seta (calcar, Fig. 16) inserted at apical three-fourths; 26 species (widespread in the Afrotropical region, including Annobón, Mauritius and Madagascar) ........................... Phaonia Robineau-Desvoidy

36'. Hind tibia without a strong posterodorsal seta (calcar) inserted on apical three-fourths.................................. 37

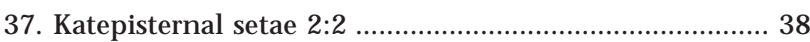

37'. Katepisternal setae different from 2:2 ........................ 39

38. Dorsal surface of vein $\mathrm{R}_{4+5}$ setulose; wings not colored as below; 18 species (widespread east to west Africa, Cameroun, Cape Verde Is., Ethiopia, Ghana, Kenya, Madagascar, Nigeria, Principe, Rhodesia, Rwanda, Seychelles, South Africa, Tanzania, Uganda, Zaire) ............ M yospila Rondani

38'. Dorsal and ventral surfaces of vein $\mathrm{R}_{4+5}$ strongly setulose at base; cross vein $\mathrm{r}-\mathrm{m}$ with a brown cloud; cross vein $\mathrm{dm}$ cu with one cloud at each end; 2 species (East Africa, Kenya, Malawi, Rhodesia Tanzania, Zaire) .... Afromydaea Malloch

39. Dorsal surface of vein $R_{4+5}$ bare; other wing veins not setulose as below; 7 species (Burundi, Comoro Is., Kenya, Madagascar, Mauritius, Rhodesia, Rwanda, South Africa, Tanzania, Zaire, widespread east to southern in the Afrotropical Region) Hebecnema Schnabl

39'. Wing veins setulose as follows: $R$ with 2-3 fine setae on lower surface before humeral cross vein; $R_{4+5}$ with 3-5 fine setae below on basal third, the setae beginning at some distance beyond the node of Rs; other veins bare above and below; 9 species (Burundi, Cameroun, Kenia, Rhodesia, São Tomé, South Africa, Tanzania, Uganda, Zaire, widespread east to southern and mainland in Afrotropical Region) ................................ Pseudohelina Vockeroth p.p.

40. Presutural dorsocentral setae absent; palpi moderately dilated (Fig. 17); 4 species (Ghana, Madagascar, Nigeria, Tanzania, Zaire) ............................... Lispacoenosia Snyder

40'. Presutural dorsocentral setae present; pal pi usually filiform ........................................................................... 41

41. Proboscis with the labella not reduced and the prestomal teeth hardly developed, and prementum dusted; prealar seta present, but if absent then sternite 1 with setulae........ 42

41 '. Proboscis with labella usually reduced and/or prestomal teeth strongly developed, and prementum shining, undusted; prealar seta absent; sternite 1 bare............... 46

42.Apical section of vein $M$ distinctly curved forward towards vein $R_{4+5}$ 43
42'. Apical section of vein $M$ straight or only slightly curved

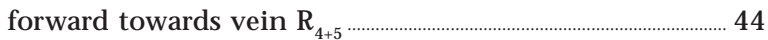

43. Three pairs of presutural dorsocentral setae; arista plumose; 1 species (not identified) (Madagascar)

Fraserella Steyskal

43'. Two pairs of presutural dorsocentral setae; arista with very short cilia; 1 species (widespread in the Afrotropical, including Annobón, Cape Verde Is., Mauritius, Seychelles) Synthesiomyia Brauer and Bergenstam

44. Hind tibia with one strong posterodorsal seta (calcar) on its apical third; anterior intralar post-sutural seta placed posteriorly to level of supralar seta; 2 species (Cape Verde Is., Réunion, St. Helena, east, northeast and southern Africa) Muscina Robneau-Desvoidy

44'. Hind tibia without calcar; anterior intralar postsutural seta placed differently as described above.......................... 45

45. Arista bare; sternite 1 with many setulae near posterior margin; prealar seta absent; male eyes large in profile and occupying most of the head; 23 species (widespread in the Afrotropical Region, including Cape Verde Is., Canary Is., Comoro Is., Madagascar, Mauritius, Réunion, Soccotra) ..

Brontaea Kowarz

45'. Arista plumose, with the longest individual hairs longer than width of flagellomere; sternite 1 usually bare; male eyes in profile not unusually large; 99 species (widespread in the Afrotropical Region, including Madagascar) ...........

Helina Robineau-Desvoidy

46. Katepisternal setae 1+1-3; ovipositor of the Mydaea-type, short, with a spinose hypoproct 47

46 . Katepisternal setae usually 1:1:1, placed at the angles of an equilateral triangle; ovipositor long, with setulose hypoproct 48

47. Arista bare; ground-colour black, entire body whitish dusted, and the head wholly white to silvery-white; small species, wing-length about $3 \mathrm{~mm}$, confined to the seashore; 1 species

New genus

47'. Arista plumose; ground-colour brown, with postpronotum yellow, body not entirely whitish dusted and head with at least interfrontalia not silvery-white; larger species, winglength about $6 \mathrm{~mm}$, species of the inland forests; 18 species (Cameroun, Ethiopia, Kenya, Liberia, Namibia,Uganda, Rhodesia, South Africa, Sudan, Zaire, Madagascar).

Spilogona Schnabl

48. Two pairs of reclinate orbital setae (Fig. 18) ................. 49

48 '. One pair of reclinate orbital setae (Fig. 19) ................... 55

49. One pair of long presutural dorsocentral setae, sometimes preceded by a very short second pair ........................... 50

49'. Two pairs of more or less subequal presutural dorsocentral setae ........................................................................ 52

50. Costal vein abbreviated ending close to tip of vein $\mathrm{R}_{4+5}$ (Fig. 20); 1 species (Nigeria, Uganda) .......... Breviscosta Malloch 50'. Costal vein not shortened ending close to tip of vein $M$

Revista Brasileira de Zoologia 24 (1): 175-184, março 2007 
(Fig. 21) 51

51. Arista with long hairs on basal half (Fig. 22); scutellum with both basal and apical pairs of setae strong; fore tibia with one median seta on posterior surface; 6 species (Cameron, Ghana, Kenya, Liberia, Madagascar, Malawi, Mauricius, Mozambique, Nigeria, Seychelles, Tanzania, Togo, Zaire, widespread west to east Africa) ............. Pygophora Schiner

51'. Arista with hairs along its entire length; scutellum with only the apical pair of setae strong, fore tibia without one median seta on posterior surface;;1 species (widespread in the Afrotropical Region, including Madagascar, Mauritius) Orchisia Rondani

52. Scutellum with the basal pair of setae very reduced or absent 53

52 '. Scutellum with the basal pair of setae well developed, as long as or longer than apical pair ................................ 54

53. Hind tibia without supramedian posterodorsal setae; profrons not projected and antennal insertion on mid-level of eye; 1 species (Tanzania, Uganda) ..... Spanochaeta Stein

53'. Hind tibia with a supramedian posterodorsal setae; profrons projected (Fig. 23) and antennal insertion above mid-level of eye; 4 species (Uganda) Amicitia Emden

54. Ocellar setae short, hair-like; outer margin of eye emarginated on basal half; hind tibia without a posteroventral seta; 3 species (1 not identified) (Madagascar)...Cephalispa Malloch

54'. Ocellar setae long; outer margin of eye not emarginated on basal half; hind tibia with a posteroventral seta; 3 species (Liberia, New Guinea, Socotra, Tanzania, Uganda, Kenya, Madagascar, Nigeria, Rhodesia, South Africa, widespread east to southern in the Afrotropical Region)

. Lispocephala Pokorny

55. Two pairs of postsutural dorsocentral setae; basal scutellar seta absent; 3 species (Ethiopia, Kenia)

Microcalyptra Stein

55'. Three pairs of postsutural dorsocentral setae; basal scutellar seta present or absent 56

56. Antennal flagellomere very long, reaching beyond epistoma, and profrons projecting (Fig. 24); frons much longer than wide; 2 pairs of strong postsutural dorsocentral setae; costa continuing around wing to apex of vein $M$; 1 species (widespread in Afrotropical Region, including Madagascar; Réunion \& Senegal, Somalia, South Africa, Tanzania; Yemen) Anaphalantus Loew

56'. Antennal flagellomere not as described above; profrons not projected; frons variable..... 57

57. Hind tibia without an anterodorsal seta in addition to the median one; 111 species (widespread in the Afrotropical Region, including Aldabra, Astove Is., Cape verde Is., Madagascar, Mauritius) ............................. Coenosia Meigen

57'. Hind tibia at least with one anterodorsal supramedian seta in addition to the median one 58
58. Frons longer than wide; antennal flagellomerelong; general body color shinning; katepisternals 1:2; lower proepimeral seta replaced by 3-4 fine hairs; 2 species (Uganda, Kenia).. Andersonosia Emden

58'. Frons wider than long (Fig. 25); antennal flagellomere short, never reaching epistome; general body color not shinning; katepisternals 1:1:1; 1 species (Ethiopia, Kenia, South Africa) Schoenomyza Haliday

\section{ACKNOWLEDGMENTS}

Part of this paper was carried out at the California Academy of Sciences, San Francisco (California) and I would like to thank all the colleagues of the Academy for their support, especially Norman D. Penny. I also thank Adrian C. Pont (Oxford University Museum of Natural History, Oxford, United Kingdom) for the useful information on the Afrotropical muscid fauna. I am also grateful to CAPES (process 3123-04-9) and to CNPq (process 300370/2004-0), agencies of the Brazilian Government fostering scientific and technological development, respectively for the Post-doctoral grant and the Research grant.

\section{REFERENCES}

Carvalho, C.J.B. de \& M.S. Couri. 2002. Part I. Basal groups, p. 17-132. In: C.J.B. de Carvalho (Ed.). Muscidae (Diptera) of the Neotropical Region: taxonomy. Curitiba, Editora Universidade Federal do Paraná, 287p.

Carvalho, C.J.B. de; M.S. Couri; A.C. Pont; D. Pamplona \& S.M. LOPES. 2005. A Catalogue of the Muscidae (Diptera) of the Neotropical Region. Zootaxa 860: 1-282p.

Couri, M.S. \& A.C. Pont. 1999. A key to the world genera of the Coenosiini (Diptera, Muscidae, Coenosiinae). Studia Dipterologica 6: 93-102.

Couri, M.S. \& A.C. Pont. 2000. Cladistic analysis of Coenosiini (Diptera: Muscidae: Coenosiinae). Systematic Entomology 25: 373-392.

Couri, M.S.; A.C. Pont \& N.D. Penny. 2006. Muscidae (Diptera) from Madagascar: keys to identification, descriptions of new species, and new records. Proceedings of the California Academy of Sciences 57 (29): 799-923.

Couri, M.S. \& C.J.B. DE Carvalho. 2002. Part II. Apical Groups, p. 133-262. In: C.J.B. de Carvalho (Ed.). Muscidae (Diptera) of the Neotropical Region: taxonomy. Editora Universidade Federal do Paraná, Curitiba, 287p.

Crosskey, R.W. 1962. A revison of the genus Pygophora Schiner (Diptera, Muscidae). Transections of the Zoological Society of London 29: 393-551.

Deeming, J.C. 1971. Some species of Atherigona Rondani (Diptera, Muscidae) from northern Nigeria, with special reference to those injurious to cereal crops. Bulletin of Entomological Research 61: 133-190.

Emden, F.I. van. 1939. Muscidae: A - Muscinae and Stomoxydinae. Ruwenzori Expedition 1934-35 2: 49-89.

Revista Brasileira de Zoologia 24 (1): 175-184, março 2007 
Emden, F.I. van. 1940. Muscidae: B - Coenosiinae. Ruwenzori Expedition. 1934-35 2: 91-255

Emden, F.I. van. 1941. Keys to the Muscidae of the Ethiopian Region: Scatophaginae, Anthomyiinae, Lispinae, Fanniinae. Bulletin of Entomological Research 32: 251-275.

Emden, F.I. van. 1942a. Keys to the Muscidae of the Ethiopian Region: Dichaetomyia-group [part]. Annals and Magazine of Natural History 9: 673-701.

Emden, F.I. van. 1942b. Keys to the Muscidae of the Ethiopian Region: Dichaetomyia-group [concl]. Annals and Magazine of Natural History 9: 721-736.

Emden, F.I. van. 1943. Keys to the Muscidae of the Ethiopian Region: Phaonia-group [part]. Annals and Magazine of Natural History 10: 73-101.

Emden, F.I. van. 1951. Muscidae: C - Scatophaginae, Anthomyiinae, Lispinae, Fanniinae and Phaoninae. Ruwenzori Expedition. 1934-35 2: 325-710.

MCALPINE, J.F. 1981. Morphology and terminology - adults, $p$. 9-63. In: J.F. M acAlpine; B.V. Peterson; G.E. Shwell; H.J. Teskey; J.R. VockeRoth \& D.M. WoOd. Manual of Nearctic Diptera. Ottawa, Research Branch, Agriculture Canada, Monograph no. 27, vol. 1, p. 1-674.

Paterson, H.E. 1960. Notes on the genus Allaudinella G.-T. with the description of a new species and a key to the known species of the genus (Diptera, Muscidae). Memoires de L'Institut Scientifique de Madagascar (E) II (1959): 355367.

Pont, A.C. 1974. A revison of the genus Passeromyia Rodhain and Villeneuve (Diptera: Muscidae). Bulletin of the British Museum of Natural History (Entomology) 30: 339-372

Pont, A.C. 1980. Family Muscidae, p. 721-761C. In: R.W. CRosskeY (Ed.). Catalogue of the Diptera of the Afrotropical Region. London, British Museum (Natutral History), 1437p.

Pont, A.C. \& F.R. Magpayo. 1995. Muscid shoot-flies of the Philippine Islands (Diptera: Muscidae, genus Atherigona Rondani). Bulletin of Entomological Research, Supplement Series, 3: 1-123.

Pont, A.C. \& J.P. Dear. 1976. A synopsis of the genus Ochromusca Malloch, 1927 (Diptera, Muscidae). Annals of the Natal Museum 22: 747-753.

SNYDER, F.M. 1953. Notes and descriptions of some Ethiopian Muscidae (Diptera). American Museum Novitates 1608: 1-21.

ZIELKE, E. 1971. Revision der Muscinae der aethiopischen Region. The Hague, W. Junk, Series entomologica, vol. 7, $199 p$.

ZIELKE, E. 1972. New Muscidae speciesfrom Madagascar (Diptera). Verhandlungen der Naturforschenden Gesel Ischaft in Basel 82 (1): 145-63.

Zumpt, F. 1969. Notes on the genusAethiopomyia Malloch (Diptera: Muscidae) with a new species from Tanzania. Journal of the Entomological Society of South Africa 32: 163-167.

Zumpt, F. 1973. The Stomoxyine biting flies of the world. Diptera: Muscidae. Taxonomy, biology, economic importance and control measures. Sttutgart, Gustav Fisher, VIII $+175 p$.

Received in 07.VII.2006; accepted in 01.III.2007. 